\title{
Analysis of Hydraulic Characteristics of Cutthroat Flume
}

\author{
Hana A. Hayawi ${ }^{1}$ \\ Dr. Ghania A. Hayawi ${ }^{3}$ \\ 1,2,3, Assistant Professor / University of Mosul / College of Engineering
}

\begin{abstract}
The aim of this research is to calculate experimentally the coefficient of discharge for cutthroat flume. Nine models were contracted with different angles $\left(\alpha=30^{\circ}, 45^{\circ}, 60^{\circ}\right)$, for each angle, Three ratios of width of cutthroat to width of channel $\mathrm{B}_{\mathrm{c}} / \mathrm{B}$ were used $\left(B_{\mathrm{c}} / \mathrm{B} \%=20,33.3,50\right)$; the slopes of the channel were changed five times $(S=0.0,0.001$, $0.002,0.003,0.004)$ for each ratio. The results show that the coefficient of discharge $C_{d}$ increases as the slope $S$ increases, and as the ratio $B_{c} / B$, is the ratio of head of water through cutthroat to width of cutthroat $h_{c} / B_{c}$, critical depth through cutthroat to width of cutthroat $\mathrm{y}_{\mathrm{c}} / \mathrm{B}_{\mathrm{c}}$ increases, and for a constant ratio $\mathrm{B}_{\mathrm{c}} / \mathrm{B}, \mathrm{C}_{\mathrm{d}}$ increases as $\alpha$ increase. An empirical model was predicted to calculate the $C_{d}$ in terms of the perimeters $\left(S, h_{c} / B_{c}, y_{c} / B_{c}, B_{c} / B\right.$, and $\left.\alpha\right)$, finally the water surface profiles were drawn and there were in a continuous trend.
\end{abstract}

Keyword: discharge coefficient, cutthroat flume

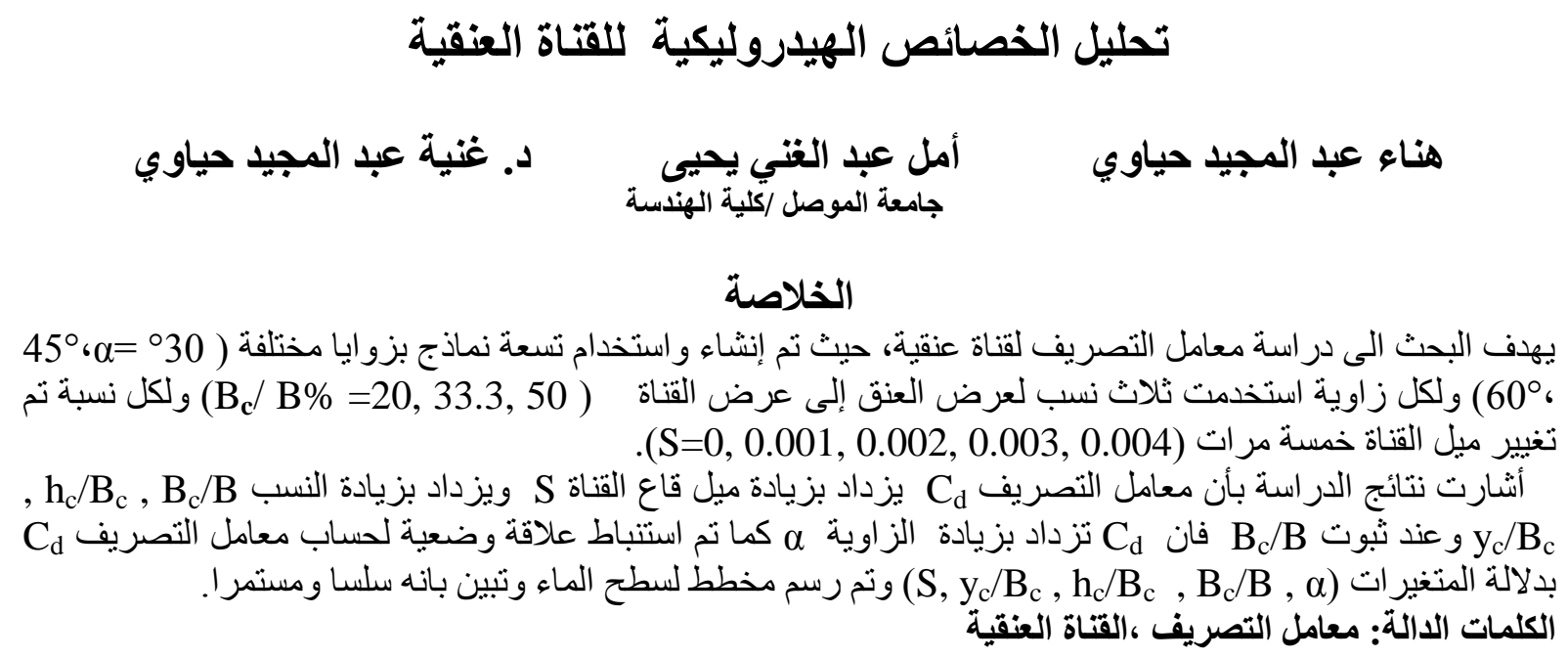

Received: 6- 5 - 2012

Accepted: $26-12-2012$ 


\section{Introduction:}

Measurement of a curate discharge is a well-known and an interesting hydraulic problem. It is useful for application objectives such as forecasting of flood discharged of a fixed return period, hydraulic design of river engineering structures and measurement of sediment transport and soil erosion (Ferro 2002a). Flumes having a local dimension of channel width are widely used as discharge measurement structures. In practice discharge measurement must not always be recorded permanently, but evaluated at various locations of a channel system (Hager 1985).

A low-cost device would be appreciated having a moderate accuracy with respect to discharged (say $= \pm 5 \%$ ). The modification to be described consists of a cylinder made of stainless steel, or high density, plastic-type material with high precision regarding its geometry. It is positioned into a channel of well-defined cross- section. Discharge then be computed using critical flow theory provided cylinder and channel geometry are known and upstream flow depth has been observed (Hager 1985). Measurement channels having flat bottom and (De Marchi et. al. 1977, Sine in Giorgio Baiamonte et. al. 2007) and parshall flumes are characterized by a particular shape of the cross-section area with various degrees of convergence and subsequent divergences. The shape aims to contract the width of the original channel in order to assure, for a free outflow condition that the critical depth occurs in the narrow section. According to (Di Stefano and Ferro 2002, sine in Giorgio Baiamonte et. al. 2007 ), the stage discharge relationship of a generic Endress+Hauser Venturimeter, characterized by a narrow section of width $\mathrm{B}_{\mathrm{C}}(\mathrm{m})$, can be expressed with the following equation:

$$
Q=1.8513 * B c^{0.9736} * h^{1.5264}
$$

In which:

$\mathrm{Q}=$ discharge measured in $\mathrm{m}^{3} \mathrm{~s}^{-1}$ : and $\mathrm{h}=$ water depth measure in $\mathrm{m}$.

Recently, a new device for measuring discharge in open channel flow was proposed by (Samani and Magallanez 2000). The measurement principle is based on establishing a channel contraction (Hager 1986, Samani and Magallanez 1993) using a cylinder which is, as (Hager 1985) asserted. The simplest body having a streamlined shape using semi cylinders applied to the walls of laboratory channel having a zero slope with width B the rectangular cross-section is narrowed to the throat width $\mathrm{B}_{\mathrm{C}}$. The diameter of the cylinders have been established for determining the chosen values of the contraction ratio $r=B_{C} / B(0.407 \leq r \leq 0.6)$. Ferro, ( 2007) depended on both the geometry of the flume and the slope of the channel in which the flume is placed. The results of laboratory investigation are reported, the runs are carried out in a laboratory channel with contraction ratio ranging from (o.17 to 0.81 ) and using in addition to the already verified zero slope flume, seven values of of slopes in the range of (0.5-3.5\%). Manekar,V. at el., (2007) established a single relation between discharge and upstream head in dimensionless form, applicable to cutthroat flumes of different sizes ,the experiment were carried on seven flumes of different ratios of length of cutthroat flume to throat width of cutthroat flume (L/W). Samani's research (2000) research included two steps(1) laboratory testing and equation development and (2) Field testing of the flume, The flume was rectangular and constructed from plywood of $3 \mathrm{~m}$ long, with $28 \mathrm{~cm}$, two cylinders of polyvinyl chloride (PVC) were attached to each of the side walls at the downstream side . Dimensionless calibration curves were developed for three different contractions of $(40 \%$, $54 \%$ and $60 \%$ ). Afield scale flume were constructed and used to measure various discharged 
rates. The measured flow rates were compared with the predicted flow rates based on the flume can be constructed at considerably less cost. The maximum submergence ratio was measured at $80 \%$. In this research the characteristics of flow through a cutthroat are studied, the proposed cutthroat was constructed by contracting the flow with placement of a triangular shape column attached to the side walls of rectangular channel as shown in(Fig.1).

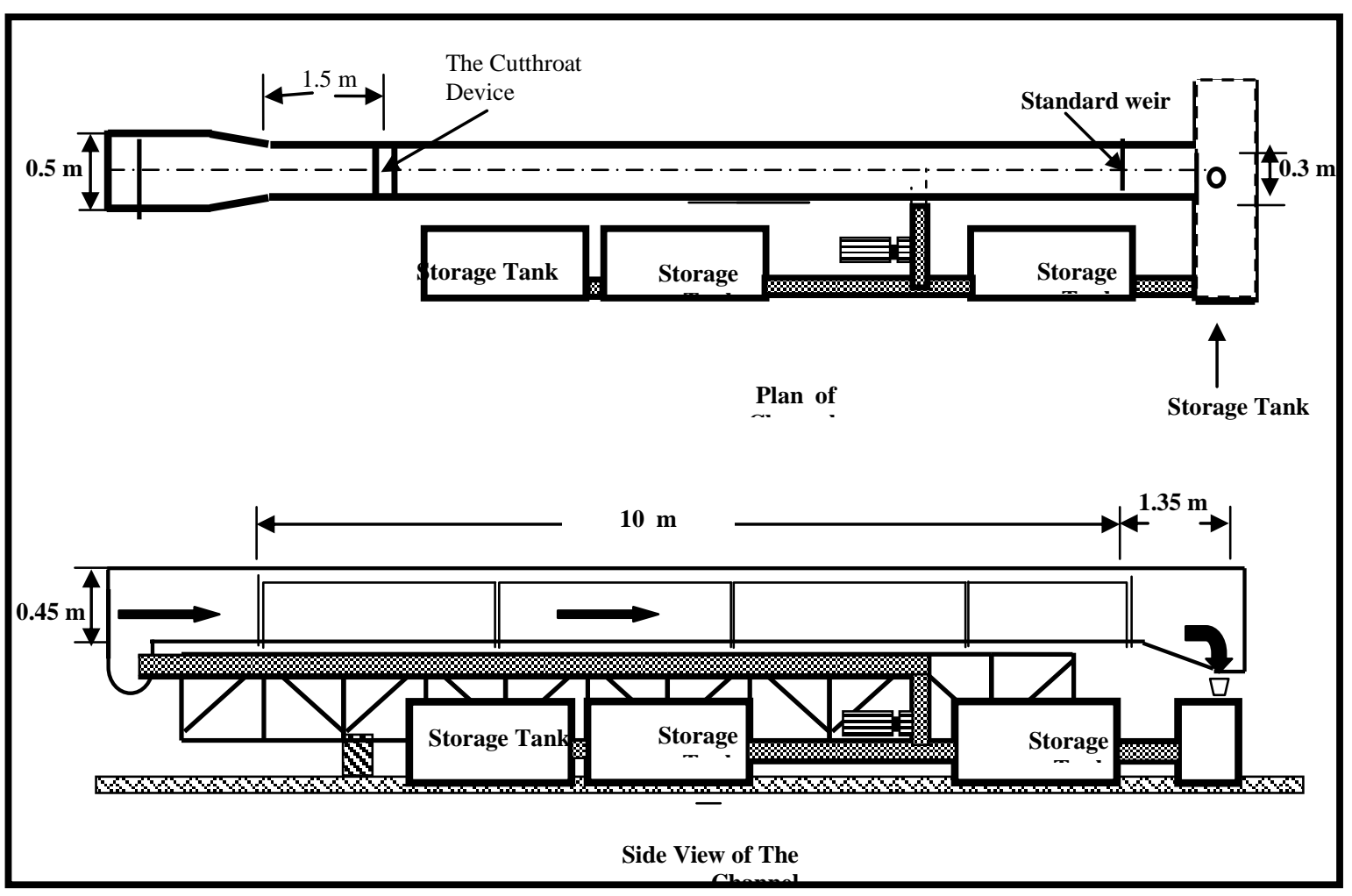

Figure (1) Channel Cross Section

\section{Experimental Set-Up and Experiment}

Experiments were carried out in the Hydraulic Laboratory of the Water Rescores Department, University of Mosul , Iraq.

The experiments were carried out in a channel of working length $10 \mathrm{~m}$, with a cross section of $0.3 \mathrm{~m}$ width and $0.45 \mathrm{~m}$ high. The walls of the channel were of toughened glass with number of perplex panels incorporated, and the bed of the channel consisted of stainless-steel plates. A pair of adjustable instrument rails were fitted on the top of the channel. Two

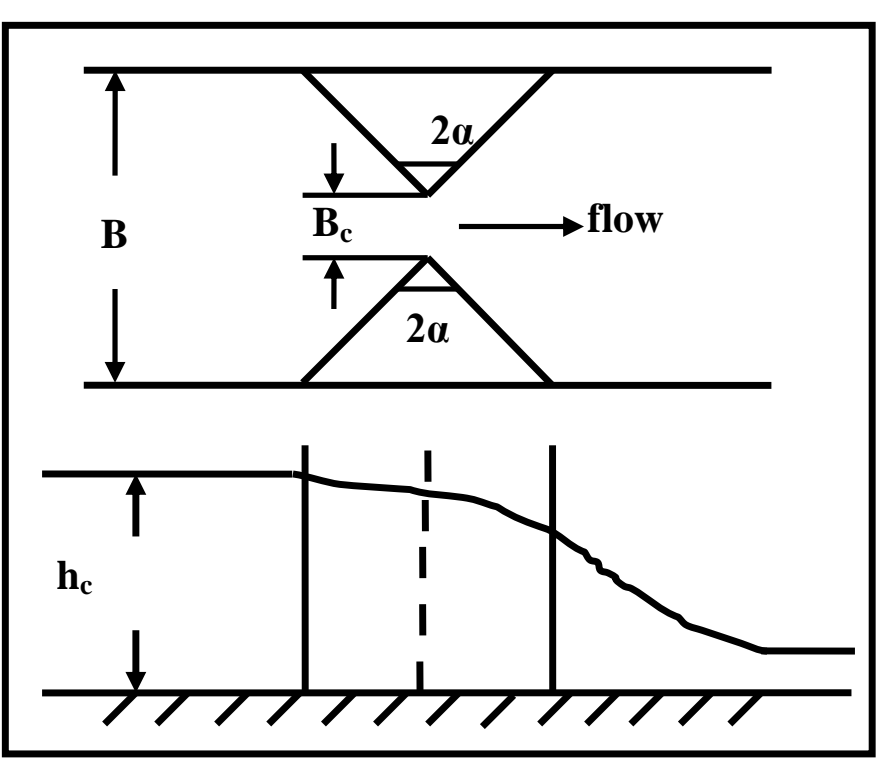

Figure (2) Details of the Tested Model 
movable carriages equipped with point gauges were mounted on the rails as shown in Fig.(1). Three groups of cutthroat models were manufactured from wooden sheet $4 \mathrm{~mm}$ thickness, each group has a triangular shape column with $\left(\alpha=30^{\circ}, 45^{\circ}, 60^{\circ}\right)$. For each angle the width of cutthroat ( $\mathrm{Bc}$ ) changed three times $(\mathrm{Bc}=6,10,15 \mathrm{~cm})$ for each $\mathrm{Bc}$ the slope of the channel is changed five times $(\mathrm{S}=0.0,0.001,0.002,0.003,0.004)$, the details of the tested models were shown in Fig.(2).

Tested model were fixed at a distance of $1.5 \mathrm{~m}$ downstream of the channel inlet, and the discharged were measured with standard full width thin plate sharp crested rectangular weir with dimensions $(15 * 30 * 1) \mathrm{cm}$ located at the outlet of the channel ,the standard weir were manufactured according to the British Standard(British Standard Institute, 1965). The centerline of the water surface profiles were recorded for each test, and the discharge passing through the cutthroat was measured with a standard weir. The water surface level and the head above the standard weir were measured with precision point gauge, whose least count was $0.4 \mathrm{~mm}$. In all tests the free falling napes at the downstream end of both the cutthroat and the standard weir were fully ventilated, more than 225 experiments were carried out through the work, the experimental program is shown in Fig(3)

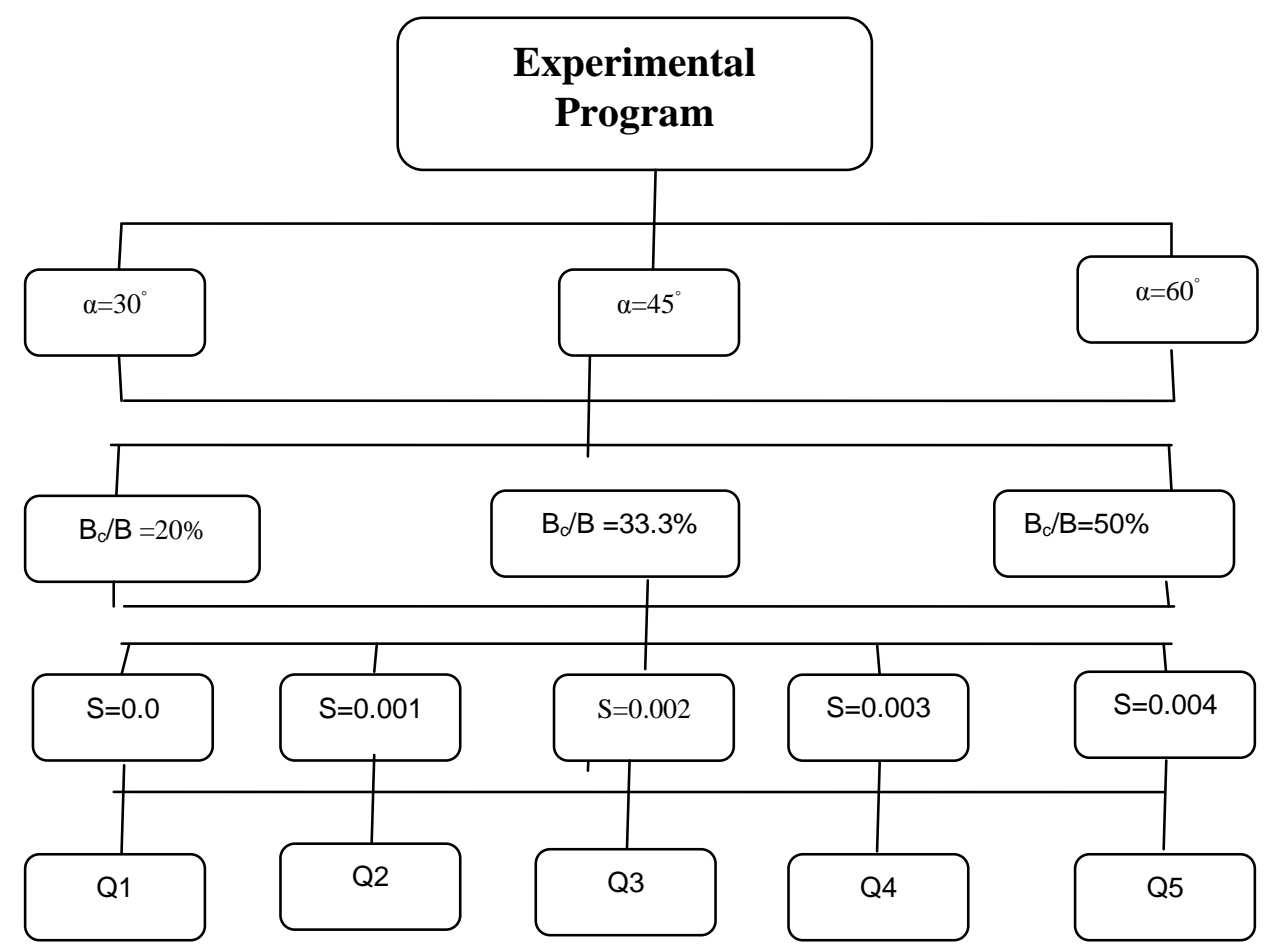

Fig. (3) The Experimental Layout

\section{Dimensional analysis}

The relationship between the depth of water upstream the cutthroat $h$ and the discharged passing through the cutthroat of width $\mathrm{Bc}$ inside a channel of width $\mathrm{B}$ and slope $\mathrm{S}$ is shown as follows(Ferro 2002a):

$C d=f(h c, B, B c, \alpha, S)$ 
Where

$\mathrm{C}_{\mathrm{d}}=$ coefficient of discharge.

hc $=$ depth of water upstream the cutthroat.

$\mathrm{B}=$ width of the channel.

$\mathrm{Bc}=$ width of the cutthroat.

$\alpha=$ the triangular angle of the column create the cutthroat.

$\mathrm{S}=$ the slope of the channel under study.

Dimensional analysis was carried out using Buckingham's pi- theorem, equation (3) may be formed as follows :

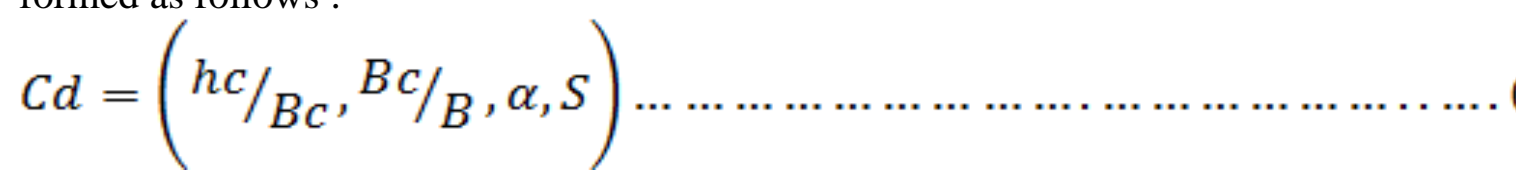

\section{Discussion and Analysis of Results:}

Using theory and laboratory experiment the coefficient of discharged $\mathrm{C}_{\mathrm{d}}$ for the cutthroat is calculated as follows:

$$
C d=Q_{\text {act }} / Q_{\text {the }}
$$

Where:

Qact $=$ Actual discharge passing through the standard weir. (العمري 2009):

$Q_{\text {act }}=0.58 * h^{1.5}$

$\mathrm{h}=$ head over standard weir.

$Q_{\text {the }}=B c *\left(g *\left(\left(\frac{2 h_{c}}{3}\right)^{3}\right)^{0.5}\right.$

Where:

$\mathrm{Q}_{\text {the:, }}$ Theoretical discharge passing through cutthroat.

The dimensional analysis shows that the coefficient of discharge $\left(\mathrm{C}_{\mathrm{d}}\right)$ depends on the ratios $\left(h_{c} / B_{c}\right),\left(y_{c} / B_{c}\right)$, the slope of the channel bed $(S)$, and the ratio $\left(B_{c} / B\right)$. The relation between coefficient of discharge $\left(\mathrm{C}_{\mathrm{d}}\right)$ and the dimensional parameters $\left(\mathrm{y}_{\mathrm{c}} / \mathrm{B}_{\mathrm{c}}\right),\left(\mathrm{h}_{\mathrm{c}} / \mathrm{B}_{\mathrm{c}}\right)$ were drawn for different ratios of $\left(\left(\mathrm{B}_{\mathrm{c}} / \mathrm{B}\right)=20 \%, 33.3 \%\right.$ and $\left.50 \%\right)$ and different channel slopes $(\mathrm{S}=0.0,0.001$, $0,002,0.003$, and 0.004$)$ and different angles $\left(\alpha=30^{\circ}, 45^{\circ}\right.$, and $\left.60^{\circ}\right)$ as discussed below:

\section{1-Variation of $\left(C_{d}\right)$ with $\left(y_{c} / B_{c}\right)$}

The relation between the coefficient of discharge $C_{d}$ and the ratio of $\left(y_{c} / B_{c}\right)$ is drawn in Figs.(4, 5, and 6) for different ratios, different angles and different slopes.

Fig.(4) shows the relation between $\left(C_{d}\right)$ and $\left(y_{c} / B_{c}\right)$ for $\left(\alpha=30^{\circ}, B_{c} / B=33.3 \%\right)$, Fig.(5)for $\left(\alpha=45, B_{c} / B=33.3 \%\right)$, and Fig(6) for $\left(\alpha=60^{\circ}, B_{c} / B=33.3 \%\right)$, these figures show the following:

a- As the ratio $\mathrm{y}_{\mathrm{c}} / \mathrm{B}_{\mathrm{c}}$ increases $\mathrm{C}_{\mathrm{d}}$ increases.

b- $\mathrm{C}_{\mathrm{d}}$ increases as the channel slope increases. 
c- When $B_{c} / B$ constant for each slope $C_{d}$ increases as $\alpha$ increases .

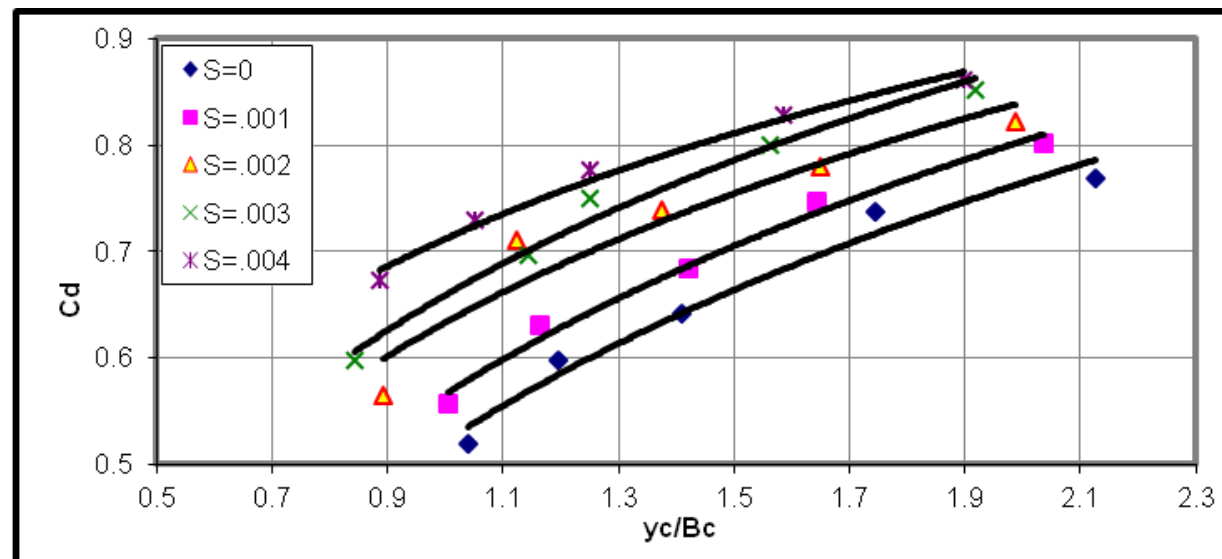

FIG (4) Variation of Coefficient of Discharge Cd With the Ratio ( $\mathrm{yclBc}$ ) For $\mathrm{Bc} / \mathrm{B}=33.3 \%$ and $\mathrm{a}=30^{\circ}$

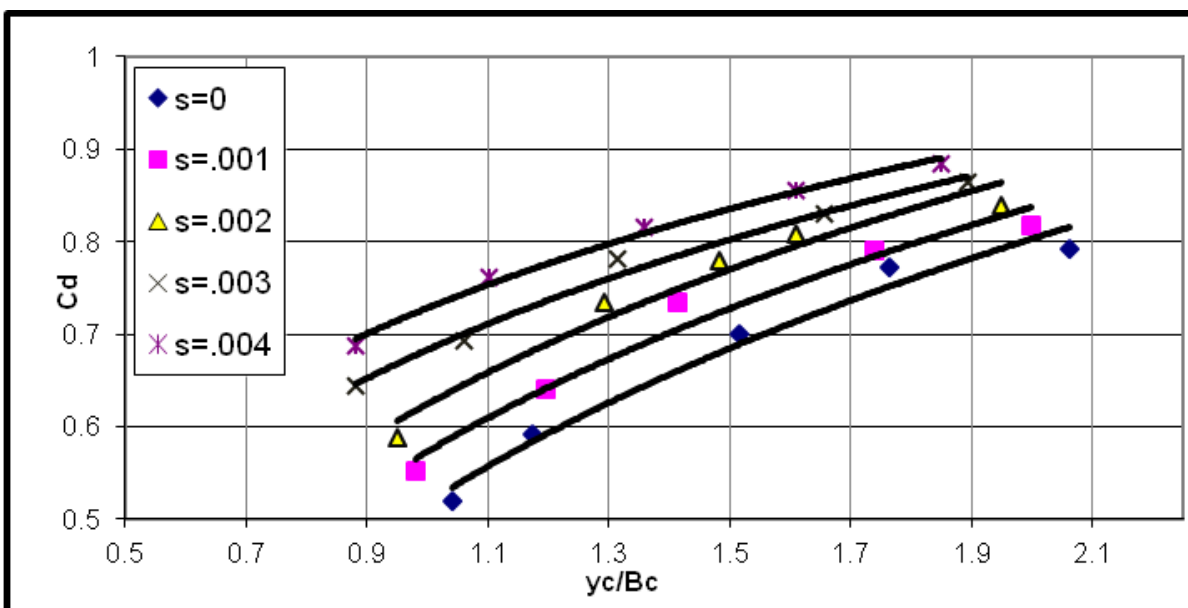

Fig (5) Variation of Coefficient of Discharge Cd With the Ratio $(\mathrm{yclBc})$ For $\mathrm{Bc} / \mathrm{B}=33.3 \%$ and $\alpha=45^{\circ}$

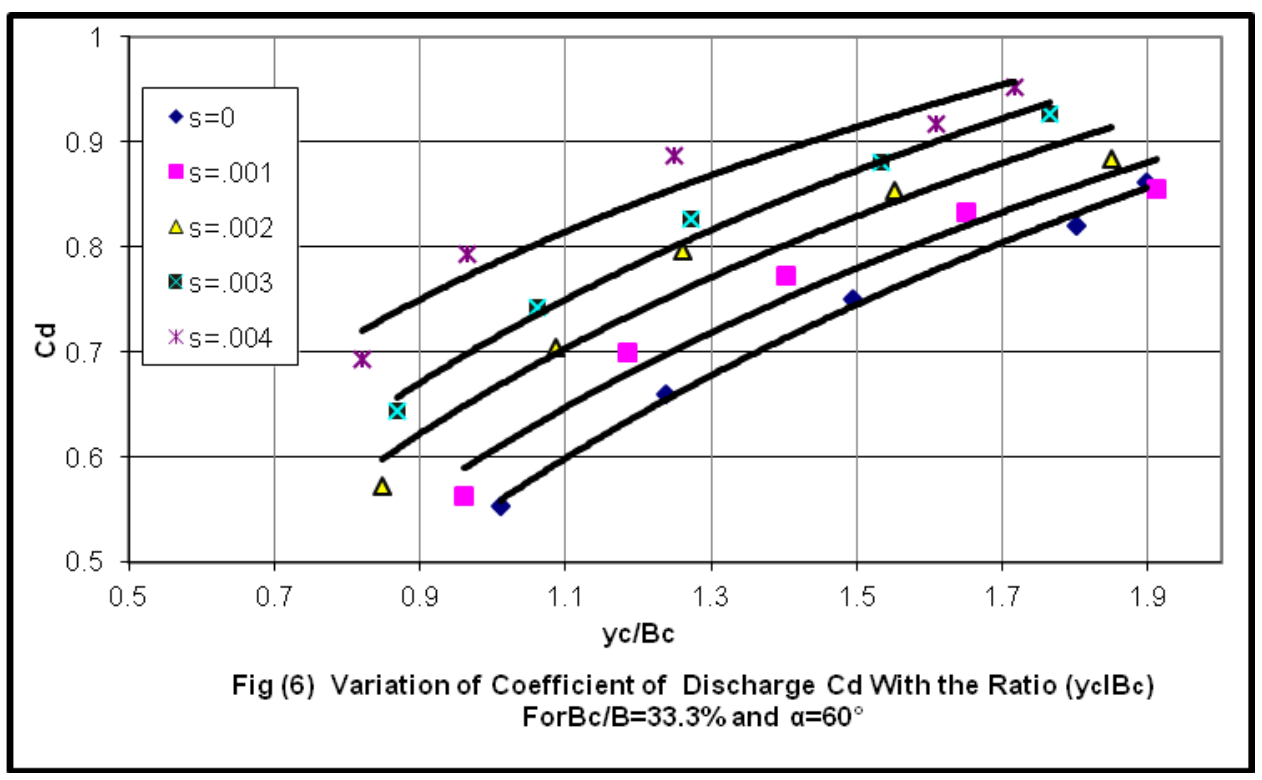




\section{2- Variation of $C_{d}$ with the ratio $h_{c} / B_{c}$}

The relation between $C_{d}$ and the ratio $h_{c} / B_{c}$ was drawn in Figs(7, 8 and 9) for different angles $\left(\alpha=30^{\circ}, 45^{\circ}\right.$, and $\left.60^{\circ}\right)$ and different channel slopes $(S=0.0,0.001,0.002,0.003$, and 0.004$)$ for $\mathrm{B}_{\mathrm{c}} / \mathrm{B}=50 \%$ respectively
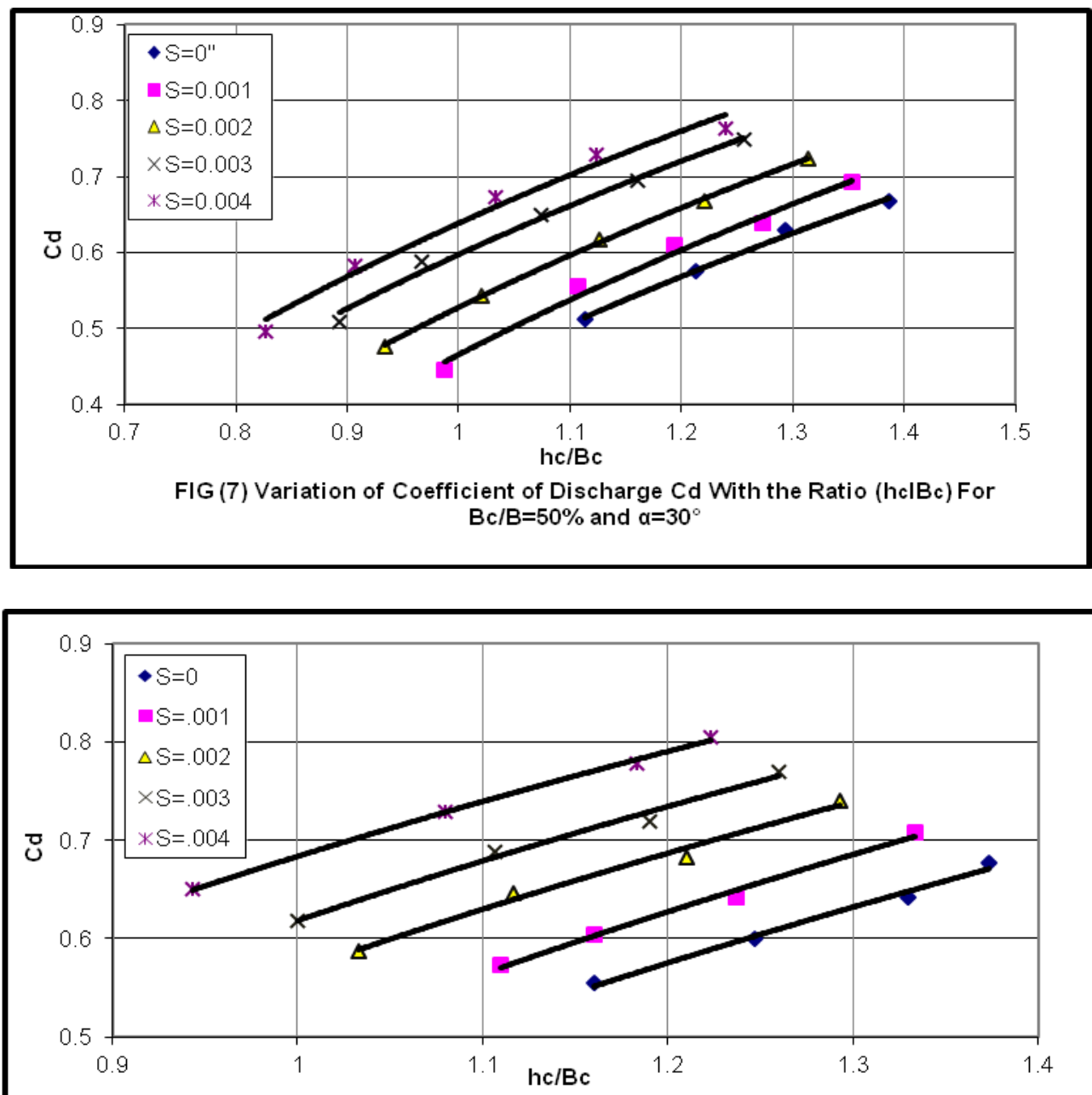

FIG (8) Variation of Coefficient of Discharge Cd With the Ratio (hclBc) For $\mathrm{Bc} / \mathrm{B}=50 \%$ and $\alpha=45$

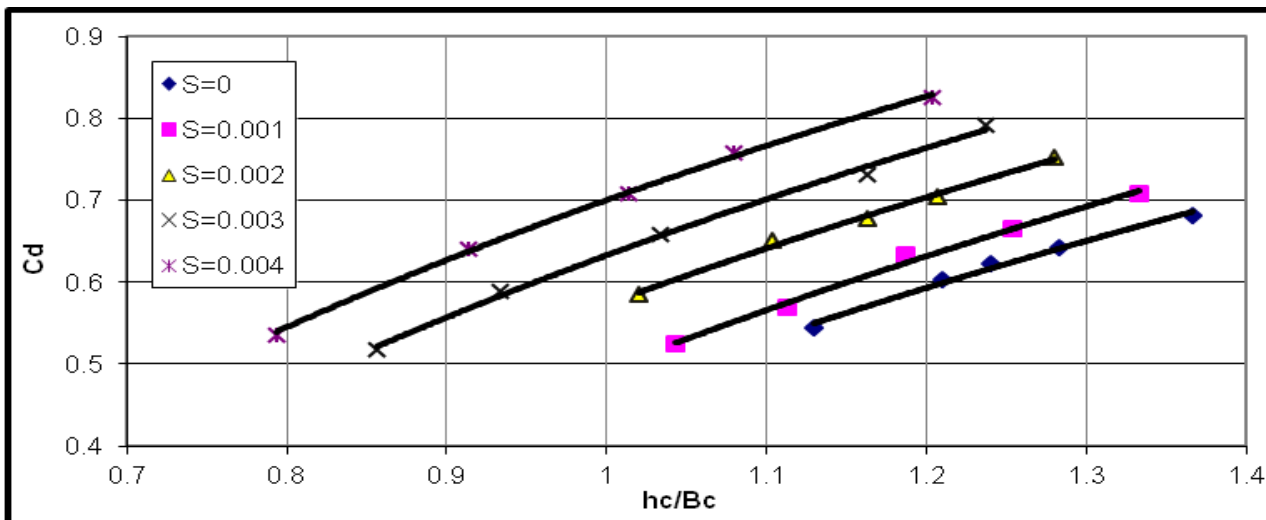

FIG (9) Variation of Coefficient of Discharge Cd With the Ratio (hclBc) For $\mathrm{Bc} / \mathrm{B}=50 \%$ and $\mathrm{a}=60^{\circ}$ 
From these Figs it is shown that:

a- $C_{d}$ increases as the ratio $h_{c} / B_{c}$ increases .

b- $\mathrm{C}_{\mathrm{d}}$ increases as the channel slope increases .

c- For each slope and for a constant ratio of $\left(B_{c} / B\right) C_{d}$ increases as $\alpha$ increases.

Fig.(10) shows the variation of $C_{d}$ with the ratio $\left(h_{c} / B_{c}\right)$ for different $\left(B_{c} / B=20 \%, 33.3 \%\right.$ and $50 \%$ ) for $\alpha=45^{\circ}, S=0.004$,

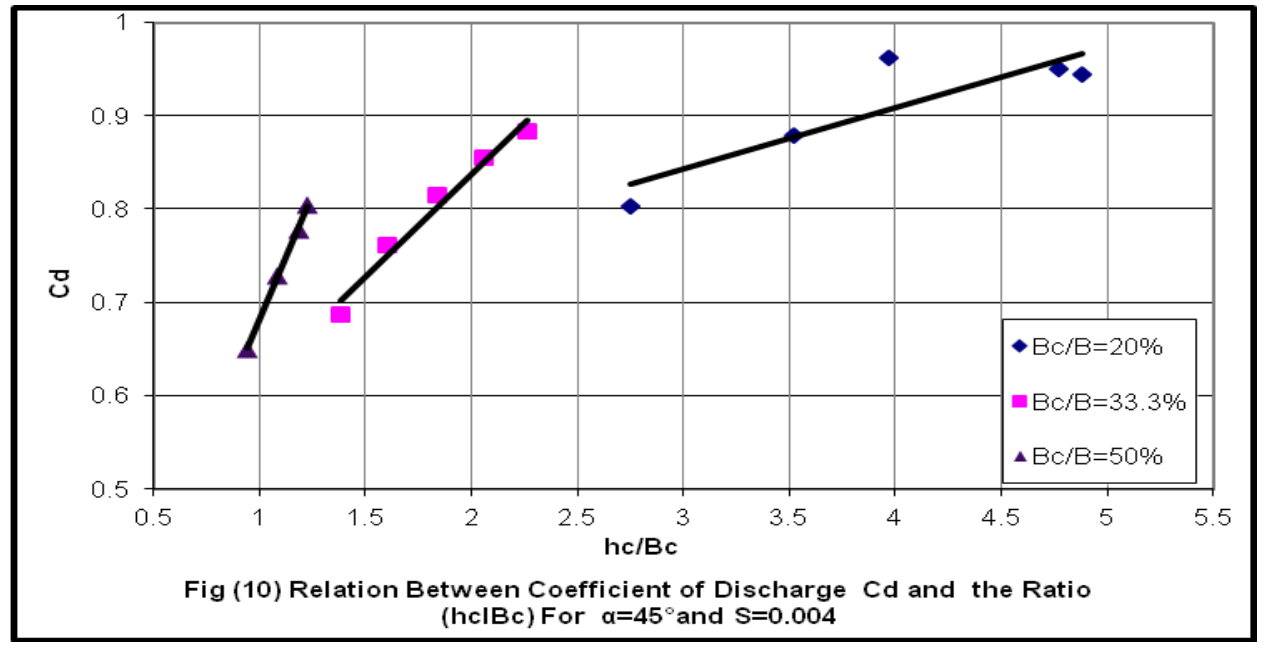

and this fig. shows for a constant $\alpha$ and a constant slope of the channel bed, $\mathrm{C}_{\mathrm{d}}$ increase as the ratio $\mathrm{B}_{\mathrm{c}} / \mathrm{B}$ decrease and the results are constant and correct for all $\alpha$ and all slopes.

\section{3- Water surface profiles:}

The experimental results of the measurement of water- surface profiles along the center line of the cutthroat show a smooth and continuous descending trend from the point of measurement to the entrance section toward the out let of the cutthroat. Figs $(11,12,13)$ show a sample of water surface profile for $\left(\alpha=30^{\circ}, 45^{\circ}\right.$, and $\left.60^{\circ}\right)$ for $\left(\mathrm{B}_{\mathrm{c}} / \mathrm{B}=50 \%\right)$ and $(\mathrm{S}=0.004)$ respectively.

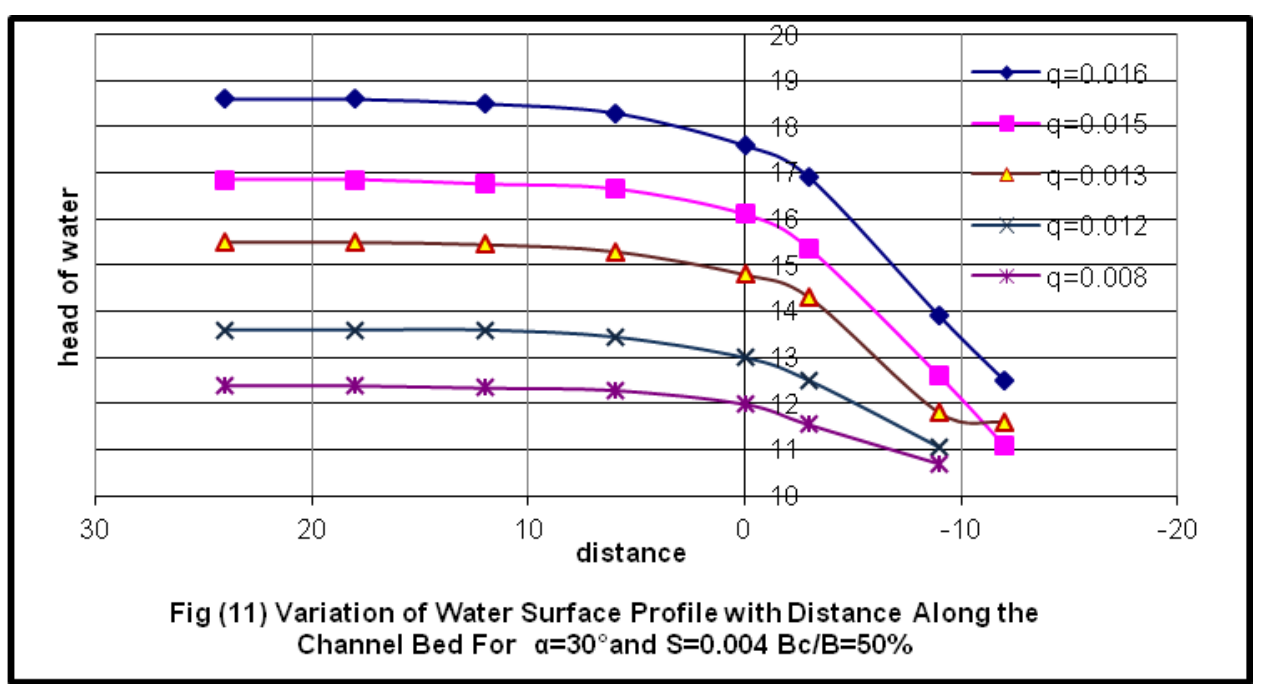




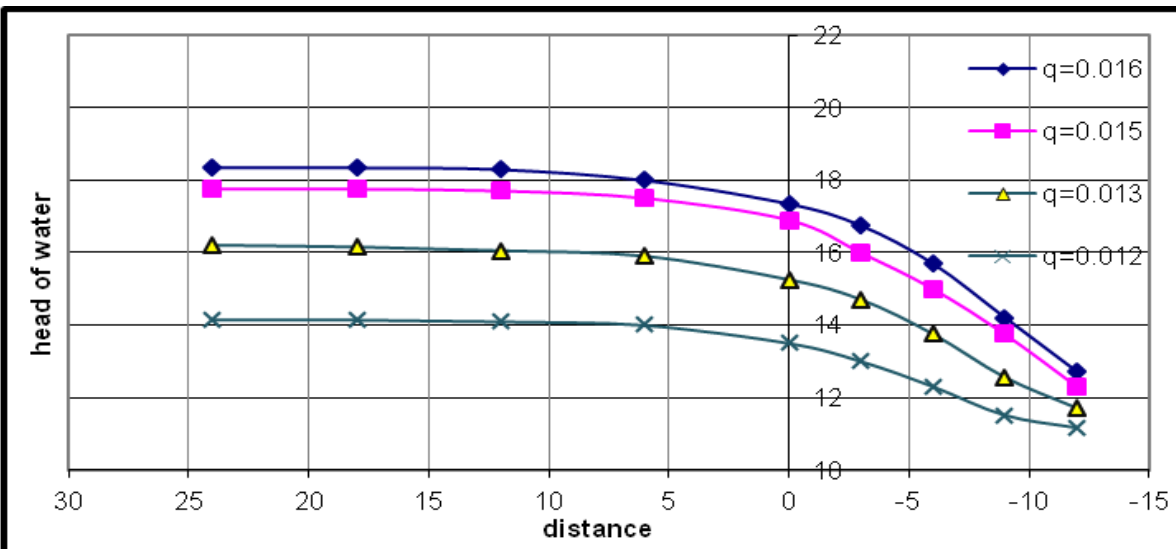

Fig (12) Variation of Water Surface Profile with Distance Along the Channel Bed For $\alpha=45^{\circ}$ and $S=0.004 \mathrm{Bc} / \mathrm{B}=50 \%$

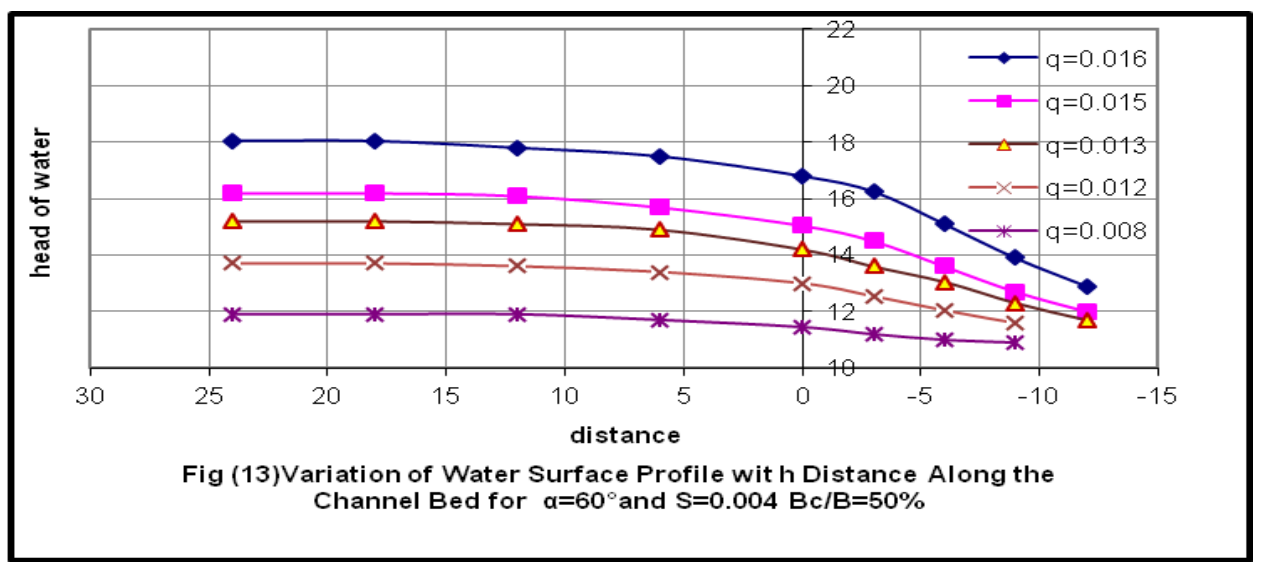

\section{4- Variation of $h_{c} / B_{c}$ with $y_{c} / B_{c}$ :}

Fig 14 shows the relation between $h_{c} / B_{c}$ and $y_{c} / B_{c}$ for $\alpha=45^{\circ}$ and $B_{c} / B=20 \%$.

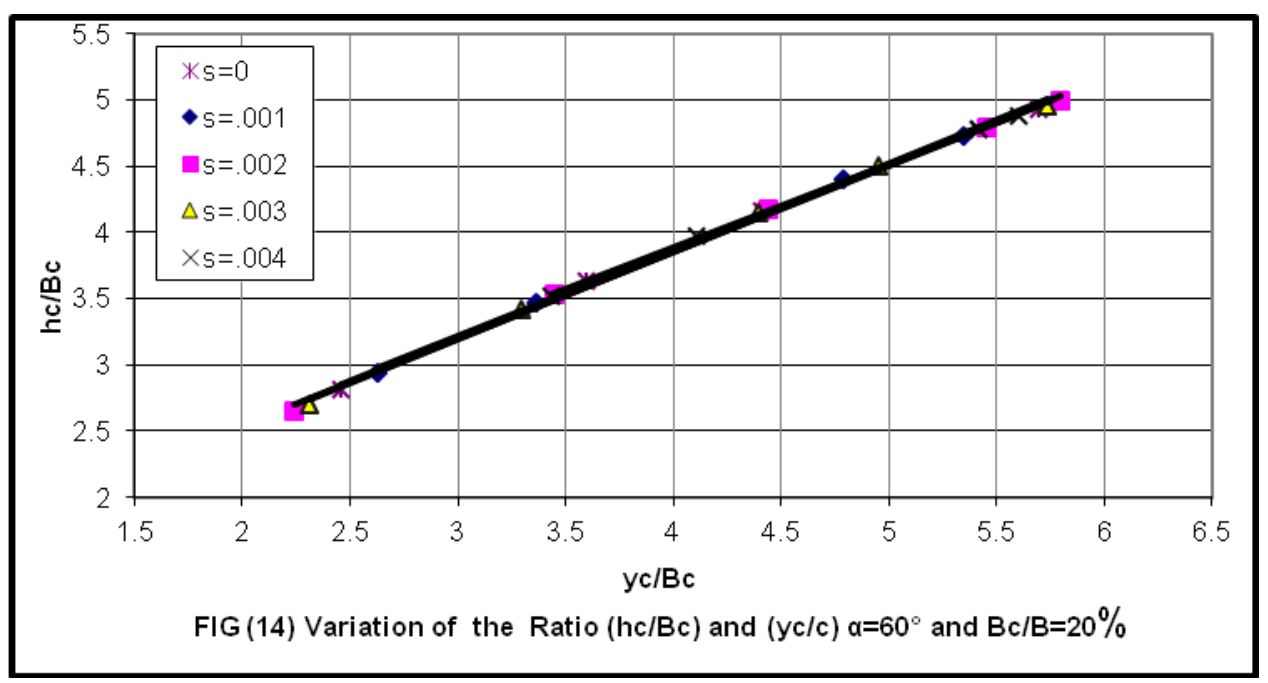


It is shown from this Fig. that the slope of the channel bed has no effect this is correct for ( $\alpha$ $=30^{\circ}$, and $\left.60^{\circ}\right)$ and for $\left(\mathrm{B}_{\mathrm{c}} / \mathrm{B}=33.3 \%\right.$ and $\left.50 \%\right)$.

\section{5-Predicted Model}

All experimental results of all cutthroat angles $(\alpha)$ all channel slopes( $S)$ and all ratios $\left(B_{c} / B\right.$ )were used as input data in (SPSS program V.11) to obtain a linear empirical relationship for variation of $C_{d}$ with the parameters $\left(h_{c} / B_{c}, S, y_{c} / B_{c}, B_{c} / B\right.$, and $\left.\alpha\right)$ in following form:

$C d=-0.5+h_{c} /_{B_{c}}+29.8 S-0.4^{y_{c}} /_{B_{c}}+0.9^{B} /_{B}+0.2 \alpha \ldots \ldots \ldots$

With correlation coefficient $\mathrm{R}^{2}=0.75$.

The relation between $C_{d}$ values predicted by equation (7) and those observed experimentally are plotted in Fig. (15) which indicate a good agreement between the calculated and predicated values of $\mathrm{C}_{\mathrm{d}}$.

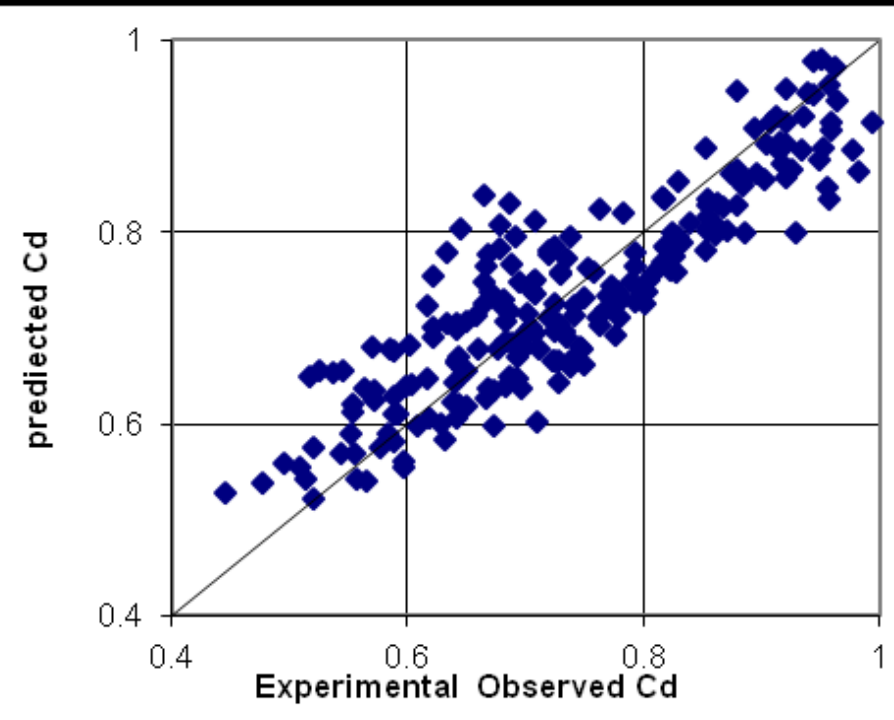

Fig (15) Variation of Predicated Values of Cd with Experimently Observed for Cutthroat

\section{Conclusions:}

From the experimental results of this study ,the following conclusions can be drawn:

1. For all channel slopes and all cutthroat angles and all ratios $B_{c} / B$ :

a. For a constant ratio $\left(B_{c} / B\right),\left(h_{c} / B_{c}\right)$ and $\left(y_{c} / B_{c}\right), C_{d}$ increases as $\alpha$ increases.

b. Coefficient of discharge $\left(C_{d}\right)$ increases as $y_{c} / B, h_{c} / B_{c}$ and, when the channel slope increases .

2.Water surface profiles along the centerline of the cutthroat show a smooth and continues descending trend from the point of measurement to the entrance section toward the outlet of the cutthroat

3. A general expression was obtained for estimation of $\left(C_{d}\right)$ with respect of $\left(B_{c} / B\right),\left(h_{c} / B_{c}\right),($ $\left.\mathrm{y}_{\mathrm{c}} / \mathrm{B}_{\mathrm{c}}\right)$, slope of the channel bed $(\mathrm{S})$, and the angle of the cutthroat $(\alpha)$. 


\section{References \\ 1- العمري نشوان (2009) ،" نأثير زاوية تفرع انحدار قعر القناة الفرعية على الجريان-دراسة مختبريه"،رسالة

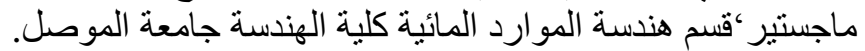

1. British Standard Institution (BSI)(1965). "Thin- Plate Weirs and Venturi Flumes in Methods of Measurement of Liquid Flow in Open Channel.", Part 4 A, BSI, 3681 BSI, London.

2. De Marchi, G. , Citrini ,D., and Noseda , G . (1977), "Noztoni di Idraulica can paricolare riguardo ai problemi delle bonifiche e delle irrigazionl.", Cdagricole, Bologna, Italy (in Italian).

3. Di Stefano, C. , and Ferro, V.(2002)."Monitoraggio dei processi erosivie calibra zione di un modollo distribuito in un picecolo bacino siciliano."Rivista di ingegneria Araria,z,47-58 (in Italian)

4. Ferro, V. (2002a). "Discussion of Simple Flume for Flow Measurement in Open Channel by Zohrab Samani and Henry Magallanez. "Journal of Irrigation and Drainage Eng. ,128(2), 129-132.

5.Giorgio Baiamonte and Vito Ferro, Phd. (2007),"Simple Flume for Flow Measurement in Sloping Open Chanel "Journal of Irrigation and Drainage Eng, ASCE, No.1, Vol. 133.

6. Hager, W. H. (1985). "Modified Venturi Channel. "Journal of Irrigation and Drainage Eng. , ASCE , 111(1) , 19-35.

7. Hager, W. H. (1986)."Modified Trapezoidal Venturi Channel."Journal of Irrigation and Drainage Eng. , ASCE,112(3) ,225-241.

8. Samani, Z. , and Magallanez, H. (1993). Measuring Water in Trapezoidal Canals. " Journal of Irrigation and Drainage Eng. , ASCE, 119(1), 181-186.

9. Samani, Z. , and Magallanez, H. (2000). "Simple Flume for Flow Measurement in Open Channel." Journal of Irrigation and Drainage Eng. , ASCE, 126(2) , 127-129.

10. Vivek. Manekar., parakash D. porey., and Ramesh N. Ingle., (2007)."Discharge Relation for Cutthroat Flume Under Free- Flow Condition." Journal of Irrigation and Drainage Eng. , ASCE, No. 5. Oct. 1, pp 495-499.

\section{List of notation:}

$\mathrm{Q}=$ Discharge measured in $\mathrm{L}^{3} \mathrm{~T}^{-1}$.

$\mathrm{h}=$ Depth of water measured in $\mathrm{L}$.

$\mathrm{h}_{\mathrm{c}}=$ Depth of water upstream cutthroat in L.

$\mathrm{B}=$ Width of channel in $\mathrm{L}$.

$\mathrm{B}_{\mathrm{c}}=$ Width of the cutthroat in $\mathrm{L}$.

$\mathrm{g}=$ Acceleration due to gravity $\mathrm{L} \mathrm{T}^{-2}$

$\mathrm{C}_{\mathrm{d}}=$ Coefficient of discharge.

$\mathrm{S}=$ Slope of the channel under study.

$\mathrm{A}=$ Triangular angle of the column create the cutthroat.

$\mathrm{Q}_{\text {act. }}=$ Actual discharge passing through the standard weir $\mathrm{L}^{3} \mathrm{~T}^{-1}$.

$\mathrm{Q}_{\text {the }}=$ Theoretical discharge passing through the cutthroat $\mathrm{L}^{3} \mathrm{~T}^{-1}$.

$\mathrm{y}_{\mathrm{c}}=$ Critical depth through the cutthroat $=\left(q^{2} / g b^{2}\right)^{1 / 3}$.

\section{The work was carried out at the college of Engineering. University of Mosul}

